\title{
PROGNOSTIC EVALUATION OF PATIENTS WITH LUMINAL B IMMUNOPHENOTYPE, SUBMITTED TO NEOADJUVANT CHEMOTHERAPY ATTENDED AT DR ARNALDO VIEIRA DE CARVALHO CANCER INSTITUTE FROM 2006 TO 2012
}

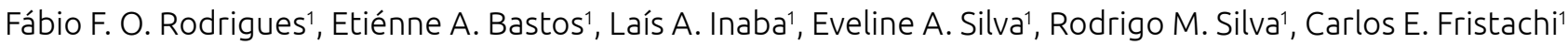
${ }^{1}$ Instituto do Câncer Doutor Arnaldo Vieira de Carvalho - São Paulo (SP), Brazil.

Objectives: Evaluate the characteristics of the patients with Luminal B breast cancer submitted to neoadjuvant chemotherapy, attended at Dr Arnaldo Vieira de Carvalho Cancer Institute from 2006 to 2012. Methods: A longitudinal study was performed, descriptive type, retrospective, of patients with invasive breast carcinoma attended at ICAVC in Sao Paulo; data were analyzed on the data base of Microsoft Excel ${ }^{\circledR}$. Results: Were evaluated 267 patients, in which 82 (31\%) presented breast neoplasm with compatible immunohistochemistry with luminal B tumors, of these, 19 (7.1\%) were submitted to neoadjuvant chemotherapy, 4 (21\%) presented pathological complete response (pCR), both mammary and axillary, 1 (5.2\%) patient presented distant metastasis for bone and none of them had local recurrence. The overall mean survival was 12 years and the disease-free survival was 4 years calculed with Kaplan Meier. Conclusion: The pCR was 21\% in patients with luminal B tumors seen in our service, with high overall survival rates due to the possibility of adjuvancy with hormonal block, wich is consistent with the data present in the current literature regarding the prognosis of such patients. 